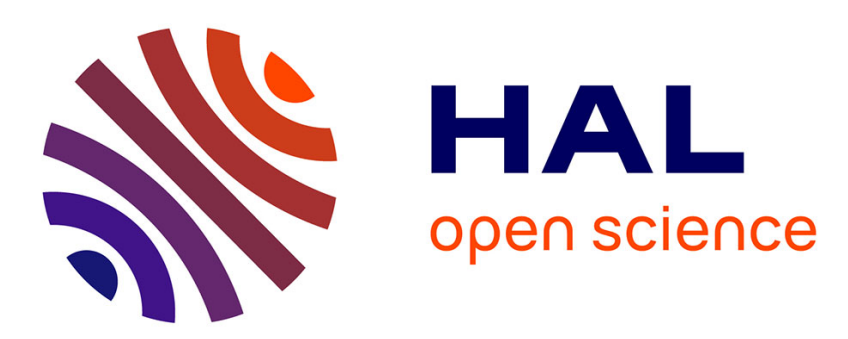

\title{
On the Influence of Slopes, Source, Seabed and Water Column Properties on T Waves: Generation at Shore
}

\author{
Alexis Bottero, Paul Cristini, Dimitri Komatitsch
}

\section{To cite this version:}

Alexis Bottero, Paul Cristini, Dimitri Komatitsch. On the Influence of Slopes, Source, Seabed and Water Column Properties on T Waves: Generation at Shore. Pure and Applied Geophysics, 2020, 177, pp.5695-5711. 10.1007/s00024-020-02611-z . hal-03014346

\section{HAL Id: hal-03014346 https://hal.science/hal-03014346}

Submitted on 16 Nov 2021

HAL is a multi-disciplinary open access archive for the deposit and dissemination of scientific research documents, whether they are published or not. The documents may come from teaching and research institutions in France or abroad, or from public or private research centers.
L'archive ouverte pluridisciplinaire HAL, est destinée au dépôt et à la diffusion de documents scientifiques de niveau recherche, publiés ou non, émanant des établissements d'enseignement et de recherche français ou étrangers, des laboratoires publics ou privés. 
Pure and Applied Geophysics manuscript No.

(will be inserted by the editor)

1 On the influence of slopes, source, seabed and water column

2 properties on $\mathrm{T}$ waves: generation at shore

3 Alexis Bottero* . Paul Cristini .

4 Dimitri Komatitsch ${ }^{\dagger}$

6 Received: date / Accepted: date

7 Abstract The term $\mathrm{T}$ waves is generally associated with acoustic waves generated

8 by seismic events that subsequently travel horizontally in the ocean at the speed

9 of sound. In this paper, we use a time-domain spectral-element method to perform a parametric study of the influence of seafloor slope, source position and media properties for a typical (downslope) T-wave generation scenario.

We find that the energy and duration of these waves are particularly sensitive to the environment. In particular, the slopes and physical characteristics of the seabed play a crucial role for both the generation and the conversion of these waves. Likewise, the depth and position of the earthquake relative to the slope is of great importance, with the presence of privileged areas for the generation of $\mathrm{T}$

17 waves, which we map.

Aix Marseille Univ., CNRS, Centrale Marseille, LMA, Marseille, France.

* Corresponding author. E-mail: alexis.bottero@gmail.com

$\dagger$ Deceased January 21, 2019 
1 Introduction

When a seismic event occurs near an ocean basin, part of the energy produced can be channeled into the water layer and then travel horizontally in this natural waveguide at the speed of sound in water. In ocean acoustics, $\mathrm{T}$ waves have been the subject of much attention since their discovery in the 1940s (Linehan, 1940). They typically have a frequency range between 1 and $100 \mathrm{~Hz}$ and can be generated from seismic waves in two main ways: by successive reflections between the sea surface and a sloping seabed (downslope conversion), or by diffraction by roughness or by heterogeneities (see Okal, 2007 for a review on the topic). In this article we will let aside $\mathrm{T}$ waves created by diffraction and focus on $\mathrm{T}$ waves generated by downslope conversion.

Once channeled into the water layer, $T$ waves can travel particularly far for several reasons. First, by propagating in the ocean, they spread in an almost cylindrical fashion, which causes less decay than in the case of spherical geometrical spreading in free space as for P and S waves (see Fox and Dziak, 1998). Second, the attenuation of acoustic waves in water is particularly low at the frequencies considered. Third, due to the fact that temperature and pressure vary with depth, the speed of sound waves in the ocean typically presents a minimum around 1000 $m$ in the Atlantic ocean. This feature, known as the Sound Fixing and Ranging (SOFAR) channel, makes it possible, under certain conditions, to facilitate energy transmission. For all these reasons, $\mathrm{T}$ waves can therefore propagate over very large distances, in practice only limited by the size of ocean basins (see Okal and Talandier, 1997; Metz et al., 2016 for example). Even a moderate seismic event can be detected thousands of kilometers away if it has generated $\mathrm{T}$ waves. Thus, the event detection threshold can be improved by one to two orders of magnitude using only a handful of instruments located either at sea (hydrophones or OBS), or in the immediate vicinity of the shore (T-phase stations) rather than large terrestrial seismic networks (Johnson and Northrop, 1966; Fox et al., 1994; De Groot-Hedlin et al., 2004; Pan and Dziewonski, 2005; Dziak et al., 2011). Nevertheless, it should 

77 Matsumoto et al., 2014).

be noted that instruments at sea may pose other problems related, for instance, to their location or to the transmission of recorded data.

After their oceanic path, $\mathrm{T}$ waves may reach the coasts. Upon arrival on the continental slope, they convert back into seismic waves that can be detected by inland seismometers Since acoustic waves travel more slowly in water than in the ground, converted T-waves typically arrive after longitudinal waves ( $\mathrm{P}$ waves, also called primary) and shear waves ( $\mathrm{S}$ waves, also called secondary), hence their name "T" as tertiary (Linehan, 1940).

However in many cases, such as small seismic events along mid-ocean spreading ridges, only $\mathrm{T}$ waves are detected. They are the only available piece of information on these events (see for example Fox et al., 1994). T waves are therefore used in many fields of geosciences. Since the 1960s, thousands of T waves have been recorded and used for earthquake location (see Johnson, 1966; Duennebier and Johnson, 1967; Fox et al., 2001) and algorithms now exist for their automatic recognition (Sukhovich et al., 2014). Although the location of the conversion zone is sometimes difficult, these measurements have made it possible to identify volcanic eruptions (Dietz and Sheehy, 1954; Norris and Johnson, 1969; Talandier and Okal, 1987; Schreiner et al., 1995; Fox and Dziak, 1998; Bohnenstiehl et al., 2013) or to monitor eruptive processes in real time (Fox et al., 1995; Dziak et al., 2011). These detections contributed greatly to our understanding of hydrothermal and microbial processes in ocean ridges (Delaney et al., 1998; Cowen et al., 2004; Wilcock et al., 2014). T waves are also very useful for detecting small intra-plate earthquakes in very remote regions (Fox et al., 2001) and for studying seafloor expansion or magma intrusion at ocean spreading ridges (Hammond and Walker, 1991; Fox et al., 1994; Schreiner et al., 1995; Blackman et al., 2000) that affect the ocean and marine ecosystems (Dziak et al., 2011, 2012). Although not caused by "earthquakes", it is interesting to note here that collisions between icebergs can also generate similar hydroacoustic signals (see e.g. Talandier et al., 2006; 
For large earthquakes in oceanic regions, $T$ waves can also be used together with $\mathrm{P}$ and $\mathrm{S}$ waves to map the different components of the fault rupture (see Graeber and Piserchia, 2004; De Groot-Hedlin, 2005; Guilbert et al., 2005; Tolstoy and Bohnenstiehl, 2005, 2006). Moreover, some links between T waves and tsunamis have now been established and could potentially be used in a warning system (Ewing et al., 1952; Tolstoy and Bohnenstiehl, 2006; Salzberg, 2008). In addition, $\mathrm{T}$ waves can also provide information on the earthquake that generated them (Dziak, 2001; Talandier and Okal, 2016), on the surface seismic characteristics of coastal regions (Koyanagi et al., 1995; Kosuga, 2011) or on the deep structure of the Wadati-Benioff zone (Okal, 2001). It is expected that $\mathrm{T}$ waves may also be used to study mesoscale variations of the ocean properties (Evers and Snellen, 2015).

Finally, acoustic signals recorded in the oceans have been used for several years to distinguish between anthropogenic and natural sources such as nuclear explosions and volcanoes, in particular under the Comprehensive Nuclear-TestBan Treaty (CTBT) adopted by the United Nations General Assembly in 1996 (see De Groot-Hedlin and Orcutt, 1999, 2001)). Indeed, the strong compressional waves generated by explosions can sometimes convert into acoustic wave traveling in the ocean which may then be detected at far distance hydroacoustically, but not seismically (see Adams, 1979).

At the interface between seismology and underwater acoustics, the T-wave phenomenon involves complex and diverse processes whose mechanisms are often poorly understood, which limits the possibilities for in-depth theoretical analysis. These processes include viscoelasticity, seismic-to-acoustic and acoustic-to-seismic conversion, slopes, diffraction, guided propagation in the ocean, high frequencies, 3-D effects, or complex geometries. In this context, it is still difficult to correctly assess the influence of the characteristics of the earthquake, the seabed or the ocean, for example. These issues are still open nowadays. In particular, they limit the correct assessment of earthquakes epicenters from T waves (see Williams et al., 
2006; Chapman and Marrett, 2006; Lecoulant et al., 2019). In particular, slopes have long been known to play a crucial role on both T-wave generation (e.g. Wadati and Inouye, 1953; Shurbet, 1955; Shurbet and Ewing, 1957; Johnson et al., 1963 ...) and conversion (e.g. Tolstoy and Ewing, 1950; Båth, 1954 ...) at shore, but their influence has not been quantified.

In this context, as in many other research areas, numerical simulation seems to be an appropriate approach for the study of $\mathrm{T}$ waves. Numerical modeling has long been used in ocean acoustics (Jensen et al., 2011), for instance based on finite elements or on parabolic equation solvers. In recent years a time-domain Spectral Element Method (SEM, Komatitsch and Tromp, 1999) has also been used successfully in the field of underwater acoustics (Cristini and Komatitsch, 2012; Jamet et al., 2013; Bottero et al., 2016; Lecoulant et al., 2019). Beyond its capability of handling complex geometries and rheologies accurately, as any finite-element technique, the time-domain spectral-element method runs efficiently on very large computers, thus providing a drastic reduction of the duration of numerical simulations, which is one of its attractive properties.

This article presents a parametric study, based on such a SEM, of the influence of seafloor slope, source position and media properties for a typical (downslope) T-wave generation scenario. The article is organized as follows: in Section 2 we describe the numerical method we use to generate the numerical results. Section 3 and 4 are then devoted to the study of the influence of slope angle on the energy of the transmitted $\mathrm{T}$ wave. In Section 5 we present some results concerning the influence of earthquake location on T-wave energy and duration. Some conclusions and perspective are drawn in Section 6.

2 The spectral-element method for ocean acoustics

The SEM is one of the most efficient numerical methods for performing numerical simulations in the time domain for the solution of the full-wave equation. In this section, we recall the main characteristics of the SEM and we focus only on some 
of its most important features. The reader is referred to the chapter 4 of reference Fichtner (2010) for more details on the method and to reference Peter et al. (2011) for a review of its capabilities for both forward and inverse modeling. The SEM is based upon a high-order piecewise polynomial approximation of the weak formulation of the wave equation. It combines the accuracy of the pseudospectral method with the flexibility of the finite-element method. In this method, the wavefield is represented in terms of high-degree Lagrange interpolants, and integrals are computed based upon Gauss-Lobatto-Legendre quadrature. This combination leads to a perfectly diagonal mass matrix, which in turn leads to a fully explicit time scheme that lends itself very well to numerical simulations on parallel computers. It is particularly well suited to handling complex geometries and interface conditions. The use of a pseudospectral method also allows for the use of coarser meshes compared to classical finite-element methods. Very distorted mesh elements can be accurately handled and complex models that include fluid, elastic, viscoelastic, anisotropic or porous media can be modeled, making the SEM a method of choice for the numerical modeling of wave propagation through various types of media encountered in ocean acoustics. This numerical method has been thoroughly validated with analytical codes and is used by many researchers in seismology all over the world . Additionally, Convolutional Perfectly Matched Layers (CPML) are used to remove spurious reflections from the boundaries of the computational domain (Komatitsch and Martin, 2007; Xie et al., 2016). Finally, the SEM is wellsuited for parallel implementations on supercomputers as well as on clusters of GPU cards by using the Message-Passing Interface (MPI) library and overlapping communications with calculations to hide their cost. This is an important feature for high-performance computing which is absolutely necessary for the configurations we are considering in the present paper. For the mesh generation, we used the meshing software Trelis (developed by Sandia National Laboratories, USA). 

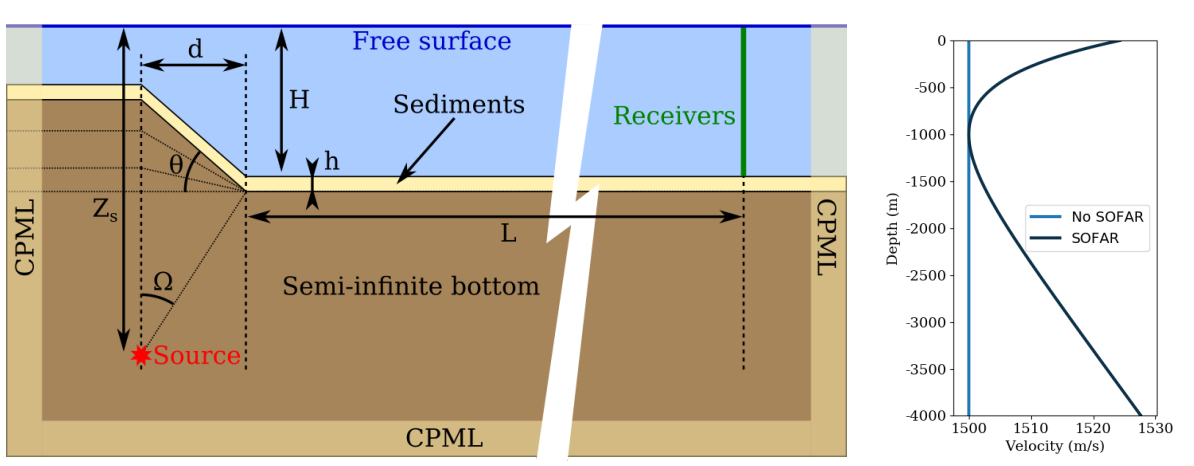

Fig. 1 Left: Setting of the study. The objective is to analyze the influence of slope angle $\theta$ and sediment properties on $\mathrm{T}$-wave energy transmitted at the green receiver line situated at range $L+d=85 \mathrm{~km}$. The geometry is $2-\mathrm{D}$ Cartesian. The source is located at depth $Z_{s}=30 \mathrm{~km}$, the sediments are $h=0.4 \mathrm{~km}$ thick, the abyssal plain is located at depth $H=4 \mathrm{~km}$, and the slope has a horizontal length of $d=5 \mathrm{~km}$. The angle $\Omega$ is fixed at 11.05 degrees. The receiver line is at $L=80 \mathrm{~km}$ from the bottom of the slope. In the spectral-element simulations the energy that reaches the edges of the model is absorbed by CPML (see text; Xie et al., 2016) absorbing layers. Right: Sound speed profiles in the sea used in the numerical simulations. The curve labeled "SOFAR" refers to a classical idealized ocean sound-speed profile (Munk, 1974) with minimum velocity at a depth of $1000 \mathrm{~m}$.

3 Common characteristics of T-wave downslope conversion, parametric study

Research on $\mathrm{T}$ waves in the late 1950s and the beginning of the 1960s had indicated that continental slopes were probably instrumental in the generation of $\mathrm{T}$ phases (e.g. Tolstoy and Ewing, 1950; Ewing et al., 1952). However, it is in the paper of Johnson et al. (1963) that the first detailed explanation of the generation mechanism of $\mathrm{T}$ waves generated by non-surficial earthquakes can be found. This article suggests that seismic energy may be trapped into the SOFAR channel after successive reflections between a downsloping seafloor and the sea surface, making it travel horizontally. This scenario, which they call downslope conversion, is based on ray tracing. T-wave amplitude is known to strongly depend on bathymetry (see e.g. Williams et al., 2006; Chapman and Marrett, 2006). This has been recently confirmed by Lecoulant et al. (2019).

We will first study the influence of slopes, seabed and water column properties on T-wave energy received at a receiver line for a typical downslope conversion scenario (Figure 1). 
This 2D Cartesian model consists of a homogeneous elastic semi-infinite bottom overlain by a $400 \mathrm{~m}$-thick homogeneous elastic sedimentary layer. The seafloor has a constant slope with a horizontal extension of $d=5 \mathrm{~km}$. The seismic source is placed right below its upper end. Contrary to a similar study carried out by Frank et al. (2015), we have chosen to keep the horizontal length of the slope constant in order to keep the solid angle from which the source sees the slope unchanged (denoted by $\Omega$ in the figure).

It is important to note here that although a 2-D Cartesian model of the slope seems to be perfectly adequate for this study, the source in this model is physically an infinite line source. With this in mind, it may seem better to work using cylindrical coordinates assuming axisymmetry rather than 2-D Cartesian coordinates. However, one would then observe multiply-reflected energy between the highest slopes and the symmetry axis that do not exist in reality ${ }^{1}$. However, fortunately, the use of 2D Cartesian coordinates rather than cylindrical coordinates is not critical for this qualitative study. It should be noted here that of course a 3-D model would be the most appropriate. Unfortunately, the number of wavelengths in the model currently makes this study impractical with "reasonable" computational resources. We believe, however, that the approximation is justified and that the results obtained would not be substantially different if considering a 3-D model. The source is placed on the downward oriented z-axis. We chose to carry the study for a shallow seismic source located in the elastic part at $Z_{s}=30 \mathrm{~km}$ below the sea surface. The receiver line is located at range $85 \mathrm{~km}$.

We consider four different sediment types, labeled LOW, MED, HIGH and "HIGH, with low density" respectively for low, medium and high velocity contrast between the crust and the water. Their properties are given in Table 1. Note that the properties labeled HIGH match the semi-infinite bottom properties, which means that there is no sedimentary layer. Note also that the case "HIGH, with

1 This could happen, though, in the case of an earthquake occurring right below a volcano or a seamount, but we are not interested in these specific cases here 
Table 1 Properties of the semi-infinite bottom and of the four types of sediments used. $\rho$ is the density, $V_{p}$ is the compressional wave speed, $V_{s}$ is the shear wave speed, and $\alpha_{p}$ and $\alpha_{s}$ are the corresponding attenuation coefficients expressed in $\mathrm{dB}$ per wavelength.

\begin{tabular}{ll}
\hline Label used & Description \\
\hline \hline Semi-infinite bottom & $\rho=2500 \mathrm{~kg} \cdot \mathrm{m}^{-3}, V_{p}=5500 \mathrm{~m} \cdot \mathrm{s}^{-1}, V_{s}=3235 \mathrm{~m} . \mathrm{s}^{-1}$ \\
& $\alpha_{p}=0.17 \mathrm{~dB} \cdot \lambda_{p}^{-1}, \alpha_{s}=0.17 \mathrm{~dB} \cdot \lambda_{s}^{-1}$ \\
\hline HIGH & $\rho=2500 \mathrm{~kg} \cdot \mathrm{m}^{-3}, V_{p}=5500 \mathrm{~m} \cdot \mathrm{s}^{-1}, V_{s}=3235 \mathrm{~m} . \mathrm{s}^{-1}$ \\
& $\alpha_{p}=0.17 \mathrm{~dB} \cdot \lambda_{p}^{-1}, \alpha_{s}=0.17 \mathrm{~dB} \cdot \lambda_{s}^{-1}$ \\
\hline MED & $\rho=2200 \mathrm{~kg} \cdot \mathrm{m}^{-3}, V_{p}=3500 \mathrm{~m} \cdot \mathrm{s}^{-1}, V_{s}=2060 \mathrm{~m} . \mathrm{s}^{-1}$ \\
& $\alpha_{p}=0.46 \mathrm{~dB} \cdot \lambda_{p}^{-1}, \alpha_{s}=0.46 \mathrm{~dB} \cdot \lambda_{s}^{-1}$ \\
\hline LOW & $\rho=2200 \mathrm{~kg} \cdot \mathrm{m}^{-3}, V_{p}=2000 \mathrm{~m} \cdot \mathrm{s}^{-1}, V_{s}=1000 \mathrm{~m} . \mathrm{s}^{-1}$ \\
& $\alpha_{p}=0.46 \mathrm{~dB} \cdot \lambda_{p}^{-1}, \alpha_{s}=0.46 \mathrm{~dB} \cdot \lambda_{s}^{-1}$ \\
\hline HIGH, with low density & $\rho=2200 \mathrm{~kg} \cdot \mathrm{m}^{-3}, V_{p}=5500 \mathrm{~m} \cdot \mathrm{s}^{-1}, V_{s}=3235 \mathrm{~m} . \mathrm{s}^{-1}$ \\
& $\alpha_{p}=0.17 \mathrm{~dB} \cdot \lambda_{p}^{-1}, \alpha_{s}=0.17 \mathrm{~dB} \cdot \lambda_{s}^{-1}$ \\
\hline
\end{tabular}

low density" is meant to highlight the effect of a variation in density only (in comparison with case HIGH).

Let us also emphasize that in this configuration, the sedimentary layer covers the whole seafloor and not only the slope. It therefore has an influence on energy transmission, not only for the T-wave conversion but also all along the propagation in the water layer. This will have to be kept in mind when comparing the results obtained with different sedimentary layers.

In the water layer, the density is equal to $1000 \mathrm{~kg} \cdot \mathrm{m}^{-3}$ and the sound velocity is either a constant velocity of $1500 \mathrm{~m} . \mathrm{s}^{-1}$ or a classical ocean sound-speed profile (Munk, 1974, see Figure 1, right). At the distance and frequencies considered the sound attenuation in the water is considered negligible (see Jensen et al., 2011).

Several numerical simulations were performed using the time-domain spectralelement method mentioned above. The source is a vertical force; its source time function is a Ricker wavelet (second derivative of a Gaussian) with a dominant frequency $f_{0}=4 \mathrm{~Hz}$. The wave field is computed up to a range of $110 \mathrm{~km}$ and down to a depth of $35 \mathrm{~km}$, the energy coming out of this box (shown in Figure 1) being absorbed by perfectly matched absorbing boundary layers. For each slope angle between 0 and $34^{\circ}$ (with an increment of one degree), eight simulations are performed, one for each of the four types of sediments in Table 1 for either a 

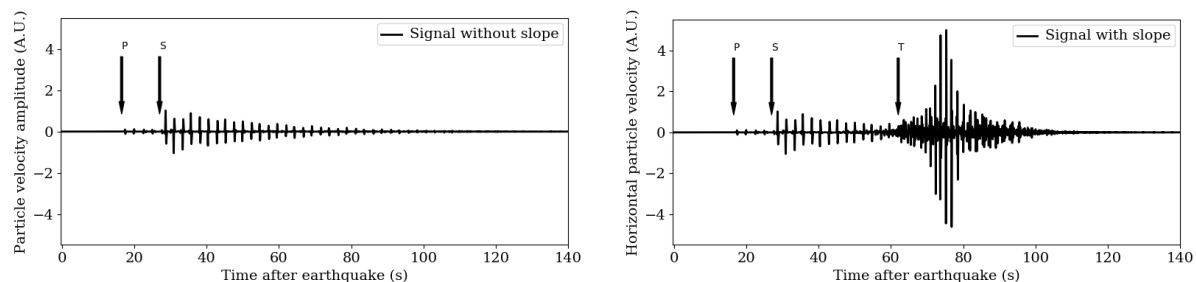

Fig. 2 Synthetic horizontal particle velocity recorded at a receiver located in the middle of the receiver line (see Figure 1) for the case labeled HIGH, with a SOFAR channel. Left: case with a reference slope of $\theta=0^{\circ}$. Right: case with a slope of $\theta=20^{\circ}$. For time $<50 \mathrm{~s}$ the two signals are almost identical and thus, in order to remove the body waves and to keep only the $\mathrm{T}$ wave, the signal on the left (corresponding to the reference slope of $\theta=0^{\circ}$ ) is subtracted from the signal on the right generated with a non-zero slope. Vertical particle velocity is similar. 
Arrivals from the P and S waves are clearly visible in both time series (they are almost identical below $40 \mathrm{~s}$ ) and do not depend on the slope. The T phase appears only in the presence of the slope, as expected. In order to remove the body waves, the reference signal for a flat bottom is subtracted from the signal generated with a slope bottom. Such processing is of course not fully satisfactory, as the signals obtained may also contain energy from other phenomena than $\mathrm{T}$ waves that may overlap with it. Nevertheless such superposition is unlikely and we suppose that it does not occur in our configurations.

4 Transmitted energy as a function of slope angle

Let us denote $u_{1}(\boldsymbol{x}, t)$ and $u_{2}(\boldsymbol{x}, t)$ the horizontal and vertical T phase displacement fields and $P(\boldsymbol{x}, t)$ the T-phase pressure field at time $t$ and position $\boldsymbol{x}=(x, z)$, obtained after subtraction of the reference signals. $\dot{u}(\boldsymbol{x}, t)=\sqrt{\dot{u}_{1}(\boldsymbol{x}, t)^{2}+\dot{u}_{2}(\boldsymbol{x}, t)^{2}}$ is the norm of the particle velocity of the $\mathrm{T}$ phase. The field that represents the instantaneous T-wave energy per unit volume in the fluid is given by (Jensen et al., 2011 pp.11-12):

$$
\mathcal{E}(\boldsymbol{x}, t)=\frac{1}{2} \rho \dot{u}^{2}(\boldsymbol{x}, t)+\frac{1}{2} \frac{P^{2}(\boldsymbol{x}, t)}{\rho(\boldsymbol{x}) c^{2}(\boldsymbol{x})},
$$

where $\rho$ is the density of water and $c(\boldsymbol{x})$ is the distribution of sound velocity. Let $T_{f}$ refer to the final time of the simulation; we can then define the integrated T-wave energy field by:

$$
E(\boldsymbol{x})=\int_{0}^{T_{f}} \mathcal{E}(\boldsymbol{x}, t) d t
$$

This quantity is similar to the radiated seismic energy introduced by Boatwright and Choy (1986) and evaluated from body wave measurements. It can also be seen as a generalization of the T-Phase Energy Flux (TPEF) proposed by Okal (2003) to characterize the part of the energy generated by an earthquake source which is converted into a T wave. This approach was used in Bottero et al. (2018) to com- 
pute broadband transmission loss maps from numerical simulations in the time domain.

Integrating $E$ over depth along the receiver line (situated at range $L+d$, see Figure 1) gives an averaged transmitted energy in the water layer:

$$
\langle E\rangle=\frac{1}{H} \int_{-H}^{0} E(L+d, z) d z
$$
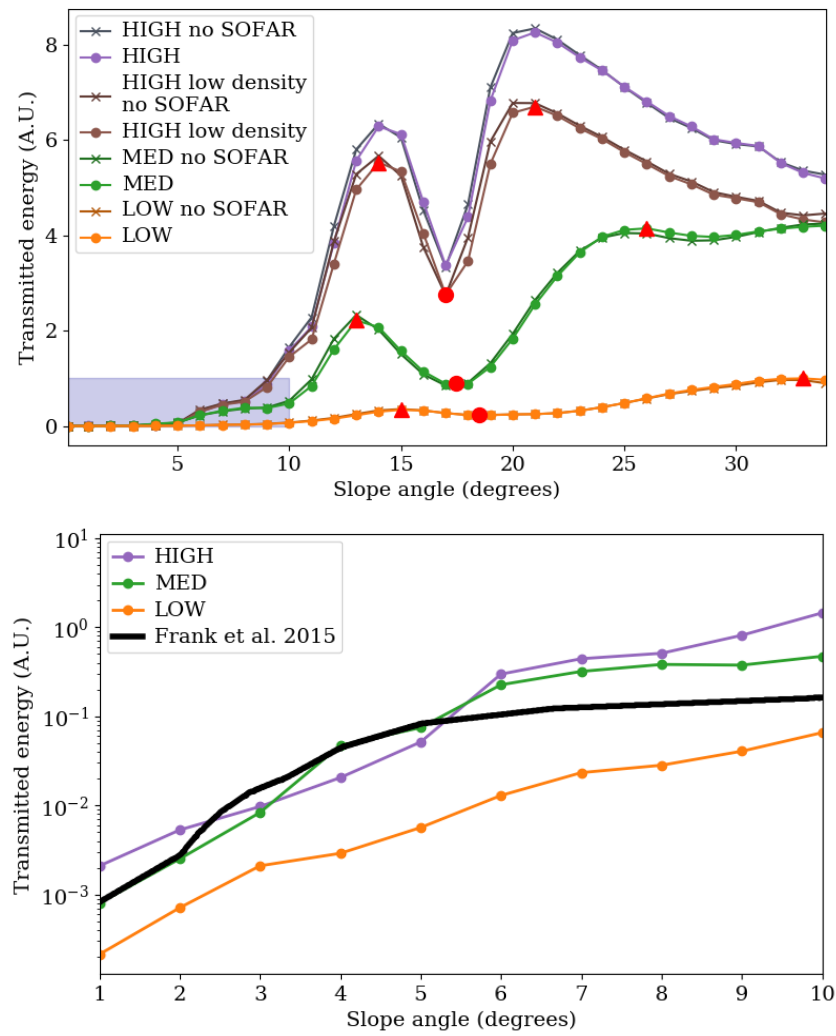

Fig. 3 Top: Transmitted T-wave energy at $85 \mathrm{~km}$ as a function of slope angle for four different sediments of Table 1 and for two different sound speed profiles in the ocean (Figure 1, right). The red triangles indicate the local maxima, and the red circle indicates the position of the trough. The blue shaded box represents the area studied by Frank et al. (2015). Bottom: Zoom on the blue shaded area of the left picture, showing also a comparison in logarithmic scale between our results and the curve shown in Frank et al. (2015) (re-scaled).

We compute the quantity $\langle E\rangle$ as a function of the slope angle for the four dif- 
in the ocean (shown in Figure 1, right). The result is shown in Figure 3 (top). The curves have a typical shape exhibiting two maxima (marked with red triangles in the figure) and a trough in between. Let us first remark that the SOFAR channel does not seem to have a significant influence on the results at this range. It can also be seen that low sediment densities penalize energy transmission without affecting the global shape of the transmission curves, as expected from Snell's law.

The particular shape of these curves can be physically explained by considering the (quasi-) plane wave reflection/transmission energy coefficients of the interfaces considered. These coefficients are shown in Figures 4 and 5 as the function of the incidence angle with respect to the normal to the surface. They were obtained numerically from parametric simulations (see Rosenkrantz et al., 2019). These coefficients take into account the two viscoelastic crustal interfaces: the transmission between the semi-infinite bottom and the different sediment configurations given in Table 1 and the reflection between the water medium (here considered as semi-infinite) and the sediments. The setting used to calculate these coefficients is illustrated in Figures 4 and 5. It should be noted here that for the transmission coefficient from the viscoelastic half-space to the water half-space the plane wave is a plane force source (thus composed of compressional and shear wave) whose direction of excitation corresponds to the direction of propagation of the plane wave. This ensures that the compressional to shear wave energy ratio in the incident plane wave is consistent with the setting considered in Figure 3 where a vertical point force has been used.

At this point, it is important to emphasize that attenuation, in particular, plays a very important role in energy reflection at the fluid/viscoelastic solid interfaces (see e.g. Carcione and Helle, 2004). This is particularly clear in Figure 5 at the top left of the middle sub-figure, for the HIGH case which shall be taken as an illustration here (even if it is actually the least attenuating case). The low-reflection band (high-transmission) around $30^{\circ}$ corresponds to the Rayleigh angle. At this incidence a large part of the energy is converted into surface waves (Stoneley- 

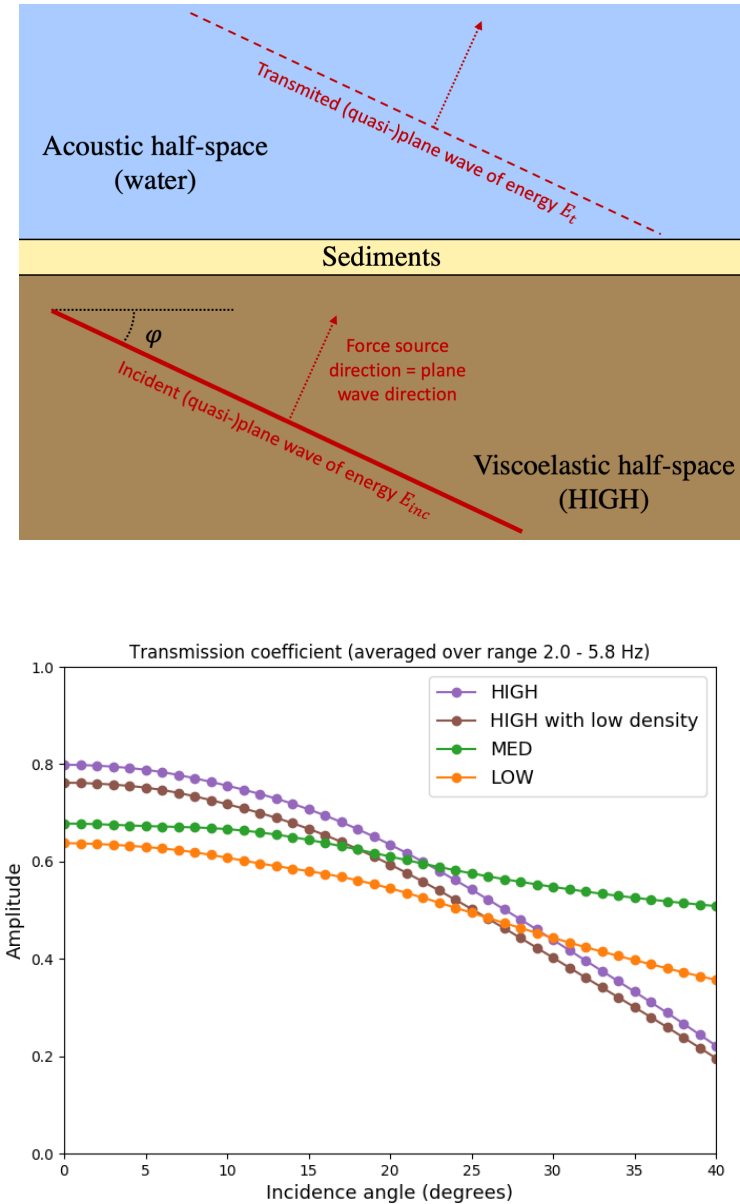

Fig. 4 Top: setting of the energy transmission coefficient shown below $\left(E_{\text {inc }} / E_{t}\right)$. Bottom: semi-infinite bottom to sediments to water energy transmission coefficient as a function of the incidence angle $\varphi$ (defined in the top sub-figure) for the cases described in Table 1 . These values have been averaged over the bandwidth of the source.

It should also be noted that the presence of a sediment layer results in a reflection coefficient that depends on frequency (see HIGH with low density, LOW and MED cases in the top of the middle sub-figure in Figure 5). To make it easier to interpret the results, the average of the coefficients around $4 \mathrm{~Hz}$ will be 

are shown in the bottom of Figure 5. For the sake of conciseness, and because they are not varying much, only these averaged curves are shown for the transmission coefficient.

From these curves and geometrical ray consideration one can then attempt to interpret Figure 3. From a zero slope to about $10^{\circ}$, when the slope increases, the amount of energy transmitted into the water column varies only slightly because the transmission coefficient is almost constant.

On the other hand, the number of reflections undergone by the wavefronts before reaching the receiver line decreases, which tends to favor better transmission. This effect is dominant compared to the variation in the reflection coefficient for subsequent reflections on the seabed.

For slopes from $10^{\circ}$ to about $18^{\circ}$ the same phenomenon continues but now the role of the reflection coefficient gets more important. At this range the wavefronts reaching the receivers (after one or several reflections on the slope) steepen from approximately $15^{\circ}$ to $30^{\circ}$. This corresponds to a sharp increase in reflection coefficient followed by a trough corresponding to the generation of surface waves (see Figure 5). This is particularly true in the cases MED and $\mathrm{HIGH}^{2}$. At the same time, the proportion of energy that reaches the slope and that is reflected, at least once on it, decreases. This results in a less horizontal propagation subsequently and thus in more reflections to reach the receivers.

These two phenomena both explain the first maximum and the following trough.

When the slope further steepens (above about $18^{\circ}$ ), the incidence angles (relative to the vertical) of the wavefronts in the water column further increase and get above about $30^{\circ}$. These values are associated with a sharp growth of the reflection coefficient at the seafloor. This strong effect prevails over all the others and explains the second steep rise of the downslope converted T-wave transmission with slope. After this angle the transmitted energy is only governed by the seabed to

2 In the case MED the reflection peak mentionned is around $22^{\circ}$ while in the case HIGH it is around $27^{\circ}$ (see Figure 5, bottom) 
water transmission coefficient, which decreases slowly, and by the reflection coefficient for incidence angles above $35^{\circ}$, which is constant in the case HIGH and fluctuates in the cases MED and LOW. These effects explain the presence of the second maximum in the curves in Figure 3.

When decreasing the impedance contrast between the water and the sediments (going from HIGH to LOW), the overall shape of the curve is preserved but is damped because of the lower average reflection coefficients.

The shift towards the higher slope angles when decreasing the impedance contrast is explained by the refraction of the incident wave at the seabed. The softer the sediments, the more vertically the energy spreads once in the water.

Figure 3 (bottom) shows a comparison of our numerical results with those of Frank et al. (2015) obtained, for small slopes, based on a parabolic equation solver. Let us mention that significant differences exist between the setting of their numerical model and ours: they used an axisymmetric geometry ${ }^{3}$, they considered a homogeneous seafloor, similar to our case labeled MED but with a lower attenuation of $\alpha_{p}=0.05 \mathrm{~dB} \cdot \lambda_{p}^{-1}, \alpha_{s}=0.10 \mathrm{~dB} \cdot \lambda_{s}^{-1}$, a $5 \mathrm{~Hz}$ monochromatic source located at $Z_{s}=10 \mathrm{~km}$ (instead of a broadband source with dominant frequency $4 \mathrm{~Hz}$ at $Z_{s}=30 \mathrm{~km}$ in our case), a receiver line at range $150 \mathrm{~km}$ (instead of 85 $\mathrm{km}$ ) and, more importantly, a different way of parameterizing the slope variations. In their model, the depth of the top of the slope is fixed and the horizontal extent of the slope consequently changes for each slope angle. This implies that the solid angle (labeled $\Omega$ in Figure 1) varies for each slope, thus favoring the lowest slopes (which receive more energy) compared to steepest ones. In our opinion, this is the main reason for the slight differences observed between the results of the two models. Nevertheless, Frank et al. (2015) reached the same conclusion in the slope range $0^{\circ}$ to $10^{\circ}$ : there is a smooth increase of transmitted energy with increasing slope angle. We have seen in this section that steeper continental

${ }^{3}$ As the parabolic equation does not take into account back-scattered energy, they do not face the problem of multiple reflections between the slope and the symmetry axis that we mentioned and that prevented us from using axisymmetric calculations in our case. 
slopes actually involve more complicated physical phenomena than gentle slopes. However, steep slopes are frequently encountered at atolls (Talandier and Okal, 1998) or at seamounts and ridges (see e.g. Chapman and Marrett, 2006). It is also worth mentioning that, in our study, the differences estimated in energy transmission between a hard (such as our case labeled HIGH for example) gently-dipping seabed (say a $5^{\circ}$ slope) and a steeper one $\left(14^{\circ}\right)$ can reach a factor of 100 , which could bias localization techniques towards steep slopes. This was already observed and documented in the literature (Northrop, 1962; De Groot-Hedlin and Orcutt, 2000), although not quantified to our knowledge. It is interesting to note that the opposite situation is also possible. Indeed, differences in energy transmission between an optimally-dipping area (i.e. a slope of $14^{\circ}$ for our case labeled HIGH for example) and a steeper slope but located in the transmission trough $\left(17^{\circ}\right)$ may bias the estimated source locations towards the lowest slopes.

\section{Influence of source position on T-wave energy and duration}

T-wave amplitude and duration are known to strongly vary depending on the position of the source with respect to the bathymetry (see e.g. Williams et al., 2006; Lecoulant et al., 2019. In this section this particular aspect will be investigated within an energy-based framework. Let us first define T-wave duration for this study. Energy and duration are two quantities of equal importance because a large energy distributed over a long period of time can go unnoticed in the presence of noise, and conversely, a limited but concentrated energy over a short period is generally more visible. In equations (1), (2) and (3) we have defined the instantaneous T-wave energy $\mathcal{E}(\boldsymbol{x}, t)$, the integrated T-wave energy $E(\boldsymbol{x})$ and the averaged transmitted $\mathrm{T}$-wave energy $\langle E\rangle$, whose computation has been detailed above. One can also define the maximum T-wave energy field:

$$
M(\boldsymbol{x})=\max _{t<T_{f}} \mathcal{E}(\boldsymbol{x}, t) .
$$


where $T_{f}$ is the physical duration of the simulation. It gives the maximum instantaneous energy at each point and provides a way of defining an "effective" T-wave duration field as:

$$
\mathcal{T}(\boldsymbol{x})=2 \frac{E(\boldsymbol{x})}{M(\boldsymbol{x})} .
$$

This quantity has the dimension of a duration, which is formally the duration of a signal considered as triangular ${ }^{4}$. Computing this field gives information on the temporal and spatial structure of the arrivals, keeping track of their spreading over time at any point of the model. As for the integrated energy, we can then define an averaged transmitted $\mathrm{T}$-wave duration in the water layer:

$$
\langle\mathcal{T}\rangle=\frac{1}{H} \int_{-H}^{0} \mathcal{T}(L+d, z) d z,
$$

which is the average effective duration of the $\mathrm{T}$ waves generated by the earthquake considered and recorded at a horizontal distance $L+d$ from the top of the slope. This approach is also used in Bottero et al. (2018) to calculate time dispersion maps from numerical simulations in the time domain.

We recall that the source we used in all our numerical simulations is a vertical force whose radiation pattern may influence the energy distribution. Nevertheless, as a first step, we chose to keep this simple source model for all numerical simulations. The study of the influence of the source radiation pattern will be considered in future studies.

To illustrate the importance of the source position on the T-wave structure, we have computed the averaged transmitted T-wave energy $\langle E\rangle$ and duration $\langle\mathcal{T}\rangle$ for 351 source positions (324 being below the seafloor level). Contrary to the previous sections, the slope does not vary and is set to $20^{\circ}$. The medium properties are those of the case labeled MED in Table 1 and we consider a sound speed profile in the water layer. Before computing the instantaneous T-wave energy $\mathcal{E}(\boldsymbol{x}, t)$, the body waves have to be subtracted from the signals. For this purpose, a reference

\footnotetext{
${ }^{4}$ In the case of triangular signals this effective duration is equal to their actual duration.
} 
run with a flat bottom is performed for each of the 324 sources below the seafloor.

For the sources situated above the ocean floor no subtraction is needed, only $\mathrm{T}$ waves are created in this case. For the sources situated below the ocean depth the horizontal and vertical displacement in the cases with and without the slope are subtracted point to point for all time and positions (see Figure 2 for an example of such signals) before computing the instantaneous energy (1) needed for the averaged energy (3) and duration (6). This subtraction procedure is not perfect for the sources situated on the left side of the slope at all depths. Especially for those located at the shallowest depths and at the greatest horizontal distances from the slope. In these cases a significant amount of the body wave energy reaching the receiver line will be different between the flat reference and the sloping model, which may result in a miscalculation of the T-wave energy. That is why the results will be later compared with and without subtraction.

The simulations were run simultaneously on 8,100 processor cores and lasted approximately one hour. The results are summarized in Figure 6.

The first, and probably the most important, point that can be made here is that these maps are not homogeneous: there are large variations in energy and duration between $\mathrm{T}$ phases generated by sources located at different positions with respect to the slope. The patterns produced are complex. We shall attempt below to interpret them.

In the vicinity of the interface between the ocean and the seafloor some artifacts can be observed. They are explained by the fact that the body waves generated with and without a slope are not strictly identical anymore for these very shallow source positions. For that reason, we will also compare the energies and durations without subtraction (i.e. including the body waves).

Let us first discuss the differences between the quantities computed from the full signal and those computed from the subtracted signals assumed to represent $\mathrm{T}$ waves only. 
Apart from the artifact, explained above, at the third line of sources the images are very similar, which means that, in most cases, body waves do not influence the results much. Consequently, the right -or the left- hand side of Figure 6 can be used for analysis.

The region right below the bottom of the slope and the outset of the abyssal plain are however exceptions to note. The results computed in this area show that $\mathrm{T}$ waves can be generated, by downslope conversion, from earthquakes located beneath the abyssal plain but only above a certain depth, contrary to body waves that can be generated at any depth. It seems that this depth increases with the distance to the slope, although this has to be confirmed by calculations over a wider area. This phenomenon could have interesting implications and explain some frequent outliers to the rule "epicenters at the lower end, and [...] seaward, of the continental slope are typically weak or not received" (Johnson et al., 1967) even without considering scattering phenomena. Example of such a signal is shown in Figure 7 (bottom) it has been recorded at range $L+d$ in the middle of the water layer from a source located at the red triangle shown on Figure 6.

It can also be noted that earthquakes that occur in the immediate vicinity of the slope are particularly prone to generate strong and impulsive (short duration) $\mathrm{T}$ waves. This result was of course expected because in that area an important part of the source energy reaches the slope and thus geometrical spreading is minimum. Besides, the angular sector under which the source sees the slope is maximum there. Looking into more details, we can see that the energy and duration maps have an interesting pattern: some regions are favored for T-wave generation and exhibit high energies and short durations.

Let us first note that, in the case considered, both $\mathrm{P}$ and $\mathrm{S}$ wave speeds in the Earth's crust (sediment and semi-infinite bottom) are greater than the sound speed in the ocean. Consequently, Snell's law implies that no energy can propagate in the ocean horizontally directly by refraction, which means that, even for sources in 
favored areas, energy transmission implies at least two reflections ${ }^{5}$. Our numerical simulations suggest that three source regions favor T-wave generation:

- The first region is situated approximately along the line starting at the top, or at the middle, of the slope and tilted by an angle of $45^{\circ}$ with respect to the vertical (dashed line in Figure 6), that is to say when the epicentral distance to the continental slope and the depth of the hypocenter are approximately the same. This region corresponds to a tradeoff between the amount of energy reflected on the slope and thus redirected towards the ocean and the grazing angles (angle with respect to the horizontal direction) of the redirected signals. Above that region the energy reflected on the slope is lower but has a smaller grazing angle, while below that region more energy is reflected but has larger grazing angle thereafter. The vicinity of the normal to the slope corresponds to the area where the solid angle from which the source sees the slope is maximum. This favored region has long been known empirically (Båth, 1954) and an interpretation based on ray tracing was made by Johnson et al. (1963). Our study also shows that the top of slopes is efficient at generating $\mathrm{T}$ waves because it allows for more energy to be redirected with low grazing angle. Let us finally note that Figure 6 shows that this favored region exhibits relatively homogeneous energy but very different durations, suggesting a variable character of $\mathrm{T}$ waves in that zone.

- The second region of interest is situated along the vertical of the slope, or along a direction slightly oriented leftward (near the solid line in Figure 6). It is in this region that we carried out the parametric study on the influence of the slope presented in the previous section. This area allows for a maximum amount of energy to be reflected on the slope. Our numerical simulations predict high amplitude and rather short duration $\mathrm{T}$ waves there.

${ }^{5}$ One could also think about a diffraction phenomenon on the sharp edges of the slope. Although we do observe this phenomenon in our simulations, the diffracted signals have negligible amplitude compared to the reflected ones 
- To a lesser extent, a third favored area is observed in Figure 6. It approximately follows a line originating at the top of the slope and oriented at $75^{\circ}$ with respect to the vertical (the dotted line in Figure 6). The energy emitted from a source in this region and reflected off the slope, although weaker, has a small grazing angle. More importantly, earthquakes located in this area are optimal for the generation of energy that propagates between the shelf and the sea surface. Due to the successive reflections on the shelf, these $\mathrm{T}$ waves have a long duration.

As an illustration, two signals of comparable energy but of different duration (ratio of $1 / 3$ ) are shown in Figure 7 (top). They have been recorded at range $L+d$ (see Figure 1) in the middle of the water layer from a source either at the blue circle or at the green square shown in Figure 6.

Earthquake magnitude and T-wave energy are known to be weakly correlated (see e.g. Okal, 2007). The main explanation for this relates to the frequency band used in estimating earthquake magnitude (anywhere from $1 \mathrm{~Hz}$ to $0.01 \mathrm{~Hz}$ or less for CMT inversions), much less than the frequencies involved in $\mathrm{T}$ phases (typically 2 to $10 \mathrm{~Hz}$ ). Note that the existence of favoured regions for $\mathrm{T}$-wave generation may reinforce this discrepancy.

Additionally, if the rupture zone crosses several areas with different transmission potentials, one can imagine that only some favored parts of the rupture, but not necessarily the most energetic, will effectively contribute to the $\mathrm{T}$ wave, which makes the phenomenon even more complex. It is also interesting to remark that for the case studied we do not observe any clear trend between source depth and signal duration for downslope generated $\mathrm{T}$ waves. However, $\mathrm{T}$-waves generated at the right of the line passing from the slope and oriented at an angle of $45^{\circ}$ with respect to the vertical (dashed line in Figure 6) tend to be of shorter duration. If onset time and duration evolve similarly (which is not necessarily true), this observation differs from the observations of Williams et al. (2006), who reported a surprising correlation between rise time and water depth above the event. This 
could suggest that the T waves observed by Williams et al. (2006) were generated by scattering rather than by downslope conversion.

6 Conclusions and future work

In this paper, new observations have been made using parametric numerical simulations. We have quantified the importance of seabed slope, seabed seismic properties, velocity profile in the ocean and source position in the generation of a two-dimensional downslope converted $\mathrm{T}$ wave. T-wave energy has been identified as particularly sensitive to the slope of the seabed, which is seen as the most important parameter, then to seismic velocities in the seabed, and finally to source position. For the quantities studied in this paper the SOFAR channel does not seem to play a significant role at least in this frequency band $(2-10 \mathrm{~Hz})$ and for short distances between epicenter and receivers $(85 \mathrm{~km})$. Our experience tells us that this will remain true for distances up to several hundred kilometers. However, this will probably no longer be the case for long propagation distances $(>5000$ $\mathrm{km})$. Low density sediments are seen to favor the generation of $\mathrm{T}$ waves by downslope conversion, as predicted by ray theory. For a given source position, downslope energy transmission is maximum for typically two slope angles. As more energy can be potentially converted at these slopes, we suggest that this can bias localization algorithms towards them, and not necessarily towards steepest slopes, as often supposed, despite the fact that it is the most common situation.

Energy and duration maps have been constructed in order to analyze the influence of the source position for a given slope. This study showed that large variations in energy and duration can exist between $\mathrm{T}$ phases generated by sources located at different positions with respect to the slope. The complex patterns observed may partly account for the documented poor correlation between earthquake magnitude and $\mathrm{T}$-wave energy (together with the different frequency bands commonly used to calculate these quantities). 
These maps also hint that $\mathrm{T}$ waves can be generated, by downslope conversion, following earthquakes that occur beneath abyssal plains, but only above a given depth depending on the distance to the slope. This observation could have interesting implications and explain some of the exceptions to the rule "epicenters at the lower end, and [...] seaward, of the continental slope are typically weak or not received" (Johnson et al., 1967).

The above results illustrate how complex T-wave generation phenomena can be. They show that the energy of these waves not only depends on the magnitude of the earthquake but also -and in comparable proportions- on the velocity of the sediments, on the position of the seismic event and on seabed bathymetry. Let us note that the radiation pattern of the source could have a significant influence as well, further increasing the complexity of the phenomenon, and would deserve a study in its own right.

Our work suggests that due to the extreme complexity of T-wave conversion and the limited availability of analytical models, earthquake localization based on T waves will be difficult to improve with conventional methods. Nevertheless the use of machine learning methods seems particularly promising in this context. The current impressive growth in this field, which manages to deal with increasingly complex problems, may probably create very significant advances in the use of $\mathrm{T}$ waves for earthquake localization using T waves. (see for example Niu et al., 2017 in the context of ocean acoustic source localization).

A companion paper dealing with the upslope conversion/reflection of $\mathrm{T}$ waves when reaching the shore will be published soon separately.

Acknowledgements D.K. would like to thank Jeroen Tromp for suggesting him to work on T waves, a long time ago. We thank also Emmanuel Le Clezio and Eric Rosenkrantz for their help in validating the reflection coefficients. We also thank Emile Okal and an anonymous reviewer for their useful comments that improved the manuscript. The Ph.D. grant of Alexis Bottero was awarded by ENS Cachan, France. This work was granted access to the French HPC resources of CINES under allocation \#A0020407165 and \#A0030410305, both made by GENCI, and of the Aix-Marseille Supercomputing Mesocenter under allocations \#b025. We 
gratefully acknowledge the support of NVIDIA Corporation with the donation of hardware for

\section{References}

Adams RD (1979) T-phase recordings at Rarotonga from underground nuclear explosions. Geophysical Journal of the Royal Astronomical Society 58(2):361369, DOI 10.1111/j.1365-246X.1979.tb01030.x

Båth M (1954) A study of T phases recorded at the Kiruna seismograph station. Tellus 6(1):63-72

Blackman DK, Nishimura CE, Orcutt JA (2000) Seismoacoustic recordings of a spreading episode on the Mohns Ridge. Journal of Geophysical Research: Solid Earth 105(B5):10961-10973

Boatwright J, Choy GL (1986) Teleseismic estimates of the energy radiated by shallow earthquakes. J Geophys Res 91(B2):2095-2112, DOI 10.1029/JB091iB02p02095

Bohnenstiehl DR, Dziak RP, Matsumoto H, Lau TKA (2013) Underwater acoustic records from the March 2009 eruption of Hunga Ha'apai-Hunga Tonga volcano in the Kingdom of Tonga. Journal of Volcanology and Geothermal Research 249:12-24, DOI 10.1016/j.jvolgeores.2012.08.014

Bottero A, Cristini P, Komatitsch D, Asch M (2016) An axisymmetric timedomain spectral-element method for full-wave simulations: Application to ocean acoustics. Journal of the Acoustical Society of America 140(5):3520-3530, DOI $10.1121 / 1.4965964$

Bottero A, Cristini P, Komatitsch D, Brissaud Q (2018) Broadband transmission losses and time dispersion maps from time-domain numerical simulations in ocean acoustics. The Journal of the Acoustical Society of America 144(3):EL222EL228

Carcione JM, Helle HB (2004) The physics and simulation of wave propagation at the ocean bottom. Geophysics 69(3):825-839 
Chapman NR, Marrett R (2006) The directionality of acoustic T-phase signals from small magnitude submarine earthquakes. Journal of the Acoustical Society of America 119(6):3669-3675, DOI 10.1121/1.2195073

Cowen JP, Baker ET, Embley RW (2004) Detection of and response to midocean ridge magmatic events: Implications for the subsurface biosphere. The Subseafloor Biosphere at Mid-Ocean Ridges pp 227-243

Cristini P, Komatitsch D (2012) Some illustrative examples of the use of a spectralelement method in ocean acoustics. Journal of the Acoustical Society of America 131(3):EL229-EL235, DOI 10.1121/1.3682459

De Groot-Hedlin C (2005) Estimation of the rupture length and velocity of the Great Sumatra earthquake of dec 26, 2004 using hydroacoustic signals. Geophysical Research Letters 32(11):n/a-n/a, DOI 10.1029/2005GL022695, 111303

De Groot-Hedlin C, Orcutt JA (1999) Synthesis of earthquake-generated T-waves. Geophysical Research Letters 26(9):1227-1230, DOI 10.1029/1999GL900205

De Groot-Hedlin C, Orcutt JA (2000) Detection of T-phases at island seismic stations: Dependence on seafloor slope, seismic velocity and roughness. Tech. rep., Scripps Institution Of Oceanography La Jolla CA

De Groot-Hedlin C, Orcutt JA (2001) Monitoring the Comprehensive NuclearTest-Ban-Treaty: Hydroacoustics. Springer

De Groot-Hedlin C, Blackman D, Orcutt J (2004) The use of hydroacoustic phases for the detection of oceanic events: Observations and numerical modeling. Tech. rep., Scripps Institution Of Oceanography La Jolla CA

Delaney JR, Kelley DS, Lilley MD, Butterfield DA, Baross JA, Wilcock WSD, Embley RW, Summit M (1998) The quantum event of oceanic crustal accretion: Impacts of diking at mid-ocean ridges. Science 281(5374):222-230

Dietz RS, Sheehy MJ (1954) Transpacific detection of Myojin volcanic explosions by underwater sound. GSA Bulletin 65(10):941, DOI 10.1130/00167606(1954)65[941:TDOMVE]2.0.CO;2 
Duennebier FK, Johnson RH (1967) T-phase sources and earthquake epicenters in the Pacific basin. Tech. rep., Hawaii Institute Of Geophysics University of Hawaii Honolulu

Dziak RP (2001) Empirical relationship of T-wave energy and fault parameters of northeast Pacific ocean earthquakes. Geophysical Research Letters 28(13):25372540, DOI 10.1029/2001GL012939

Dziak RP, Hammond SR, Fox CG (2011) A 20-year hydroacoustic time series of seismic and volcanic events in the northeast Pacific ocean. Oceanography 24

Dziak RP, Bohnenstiehl DR, Smith DK (2012) Hydroacoustic monitoring of oceanic spreading centers: Past, present, and future. Oceanography 25(1):116127

Evers LG, Snellen M (2015) Passive probing of the sound fixing and ranging channel with hydro-acoustic observations from ridge earthquakes. Journal of the Acoustical Society of America 137(4):2124-2136

Ewing M, Press F, Worzel JL (1952) Further study of the T phase. Bull seism Soc Am 42:37-51

Fichtner A (2010) Full Seismic Waveform Modelling and Inversion. Advances in Geophysical and Environmental Mechanics and Mathematics, Springer-Verlag, Berlin, Germany, 343 pages.

Fox CG, Dziak RP (1998) Hydroacoustic detection of volcanic activity on the Gorda ridge, February-March 1996. Deep Sea Research Part II: Topical Studies in Oceanography 45(12):2513-2530, DOI 10.1016/S0967-0645(98)00081-2

Fox CG, Dziak RP, Matsumoto H, Schreiner AE (1994) Potential for monitoring low-level seismicity on the Juan de Fuca Ridge using military hydrophone arrays. Marine Technology Society Journal 27(4):22-30

Fox CG, Radford WE, Dziak RP, Lau TK, Matsumoto H, Schreiner AE (1995) Acoustic detection of a seafloor spreading episode on the juan de fuca ridge using military hydrophone arrays. Geophysical Research Letters 22(2):131-134 
Fox CG, Matsumoto H, Lau TKA (2001) Monitoring Pacific Ocean seismicity from an autonomous hydrophone array. Journal of Geophysical Research: Solid Earth 106(B3):4183-4206

Frank SD, Collis JM, Odom RI (2015) Elastic parabolic equation solutions for oceanic T-wave generation and propagation from deep seismic sources. Journal of the Acoustical Society of America 137(6):3534-3543

Graeber FM, Piserchia PF (2004) Zones of T-wave excitation in the NE Indian ocean mapped using variations in backazimuth over time obtained from multichannel correlation of IMS hydrophone triplet data. Geophysical Journal International 158(1):239-256

Guilbert J, Vergoz J, Schissele E, Roueff A, Cansi Y (2005) Use of hydroacoustic and seismic arrays to observe rupture propagation and source extent of the $\mathrm{Mw}=9.0$ Sumatra earthquake. Geophysical Research Letters 32(15), DOI 10.1029/2005GL022966

Hammond SR, Walker DA (1991) Ridge event detection: T-phase signals from the Juan de Fuca spreading center. Marine Geophysical Researches 13(4):331-348, DOI 10.1007/BF00366282

Jamet G, Guennou C, Guillon L, Mazoyer C, Royer JY (2013) T-wave generation and propagation: A comparison between data and spectral element modeling. Journal of the Acoustical Society of America 134(4):3376-3385

Jensen FB, Kuperman W, Porter M, Schmidt H (2011) Computational Ocean Acoustics, 2nd edn. Springer-Verlag, Berlin, Germany, 794 pages.

Johnson RH (1966) Routine location of T-phase sources in the Pacific. Bulletin of the Seismological Society of America 56(1):109-118

Johnson RH, Northrop J (1966) A comparison of earthquake magnitude with Tphase strength. Bulletin of the Seismological Society of America 56(1):119-124 Johnson RH, Northrop J, Eppley R (1963) Sources of Pacific T phases. Journal of Geophysical Research 68(14):4251-4260, DOI 10.1029/JZ068i014p04251 
Johnson RH, Norris RA, Duennebier FK (1967) Abyssally generated T phases. Tech. rep., Hawaii Institute Of Geophysics University of Hawaii Honolulu Komatitsch D, Martin R (2007) An unsplit convolutional perfectly matched layer improved at grazing incidence for the seismic wave equation. Geophysics 72(5):SM155-SM167

Komatitsch D, Tromp J (1999) Introduction to the spectral-element method for 3D seismic wave propagation. Geophys J Int 139(3):806-822, DOI 10.1046/j.1365246x.1999.00967.x

Kosuga M (2011) Localization of T-wave energy on land revealed by a dense seismic network in japan. Geophysical Journal International 187(1):338-354

Koyanagi S, Aki K, Biswas N, Mayeda K (1995) Inferred attenuation from site effect-corrected $\mathrm{T}$ phases recorded on the island of Hawaii. Pure and Applied Geophysics 144(1):1-17

Lecoulant J, Guennou C, Guillon L, Royer JY (2019) Three-dimensional modeling of earthquake generated acoustic waves in the ocean in simplified configurations. The Journal of the Acoustical Society of America 146(3):2113-2123, DOI $10.1121 / 1.5126009$

Linehan SJD (1940) Earthquakes in the West Indian region. Transactions American Geophysical Union 21:229-232

Matsumoto H, Bohnenstiehl DR, Tournadre J, Dziak RP, Haxel JH, Lau TK, Fowler M, Salo SA (2014) Antarctic icebergs: A significant natural ocean sound source in the southern hemisphere. Geochemistry, Geophysics, Geosystems 15(8):3448-3458

Metz D, Watts AB, Grevemeyer I, Rodgers M, Paulatto M (2016) Ultralong-range hydroacoustic observations of submarine volcanic activity at Monowai, Kermadec Arc. Geophysical Research Letters 43(4):1529-1536, DOI 10.1002/2015GL067259

Munk WH (1974) Sound channel in an exponentially stratified ocean, with application to SOFAR. Journal of the Acoustical Society of America 55(2):220-226 
Niu H, Reeves E, Gerstoft P (2017) Source localization in an ocean waveguide using supervised machine learning. Journal of the Acoustical Society of America 142(3):1176-1188, DOI 10.1121/1.5000165

Norris RA, Johnson RH (1969) Submarine volcanic eruptions recently located in the pacific by SOFAR hydrophones. Journal of Geophysical Research 74(2):650664

Northrop J (1962) Evidence of dispersion in earthquake T phases. Journal of Geophysical Research 67(7):2823-2830, DOI 10.1029/JZ067i007p02823

Okal EA (2001) "Detached" deep earthquakes: Are they really? Physics of the Earth and Planetary Interiors 127(1):109-143

Okal EA (2003) T waves from the 1998 Papua New Guinea earthquake and its aftershocks: Timing the tsunamigenic slump. Pure and Applied Geophysics 160(10):1843-1863, DOI 10.1007/s00024-003-2409-x

Okal EA (2007) The generation of T waves by earthquakes. Adv Geophys 49:1-65

Okal EA, Talandier J (1997) T waves from the great 1994 Bolivian deep earthquake in relation to channeling of S wave energy up the slab. Journal of Geophysical Research: Solid Earth 102(B12):27421-27437, DOI 10.1029/97JB02718

Pan J, Dziewonski AM (2005) Comparison of mid-oceanic earthquake epicentral differences of travel time, centroid locations, and those determined by autonomous underwater hydrophone arrays. Journal of Geophysical Research: Solid Earth 110(B7)

Peter D, Komatitsch D, Luo Y, Martin R, Le Goff N, Casarotti E, Le Loher P, Magnoni F, Liu Q, Blitz C, Nissen-Meyer T, Basini P, Tromp J (2011) Forward and adjoint simulations of seismic wave propagation on fully unstructured hexahedral meshes. Geophys J Int 186(2):721-739, DOI 10.1111/j.1365246X.2011.05044.x

Rosenkrantz E, Bottero A, Komatitsch D, Monteiller V (2019) A flexible numerical approach for non-destructive ultrasonic testing based on a time-domain spectral-element method: Ultrasonic modeling of lamb waves in immersed de- 
fective structures and of bulk waves in damaged anisotropic materials. NDT \&

E International 101:72-86

Salzberg D (2008) A hydro-acoustic solution to the local tsunami warning problem.

In: AGU Fall Meeting Abstracts

Schreiner AE, Fox CG, Dziak RP (1995) Spectra and magnitudes of T-waves from the 1993 earthquake swarm on the Juan de Fuca Ridge. Geophysical Research Letters 22(2):139-142, DOI 10.1029/94GL01912

Shurbet DH (1955) Bermuda T phases with large continental paths. Bulletin of the Seismological Society of America 45(1):23-35

Shurbet DH, Ewing M (1957) T phases at Bermuda and transformation of elastic waves. Bulletin of the Seismological Society of America 47(3):251-262

Sukhovich A, Irisson JO, Perrot J, Nolet G (2014) Automatic recognition of T and teleseismic $\mathrm{P}$ waves by statistical analysis of their spectra: An application to continuous records of moored hydrophones. Journal of Geophysical Research: Solid Earth 119(8):6469-6485

Talandier J, Okal EA (1987) Seismic detection of underwater volcanism: The example of French Polynesia. Pure and Applied Geophysics 125(6):919-950

Talandier J, Okal EA (1998) On the mechanism of conversion of seismic waves to and from T waves in the vicinity of island shores. Bull seism Soc Am 88(2):621632

Talandier J, Okal EA (2016) A new source discriminant based on frequency dispersion for hydroacoustic phases recorded by T-phase stations. Geophysical Journal International 206(3):1784-1794, DOI 10.1093/gji/ggw249

Talandier J, Hyvernaud O, Reymond D, Okal EA (2006) Hydroacoustic signals generated by parked and drifting icebergs in the southern indian and pacific oceans. Geophysical Journal International 165(3):817-834

Tolstoy I, Ewing M (1950) The T phases of shallow-focus earthquakes. Bull seism Soc Am 40:25-51 
Tolstoy M, Bohnenstiehl DR (2005) Hydroacoustic constraints on the rupture duration, length, and speed of the great Sumatra-Andaman earthquake. Seismological Research Letters 76(4):419-425

Tolstoy M, Bohnenstiehl DR (2006) Hydroacoustic contributions to understanding the December 26th 2004 great Sumatra-Andaman earthquake. Surveys in Geophysics 27(6):633-646, DOI 10.1007/s10712-006-9003-6

Wadati K, Inouye W (1953) On the T phase of seismic waves observed in Japan. Proc Japan Acad 29:47-54

Wilcock WSD, Stafford KM, Andrew RK, Odom RI (2014) Sounds in the ocean at 1-100 Hz. Annual review of marine science 6:117-140

Williams CM, Stephen RA, Smith DK (2006) Hydroacoustic events located at the intersection of the Atlantis $\left(30^{\circ} \mathrm{N}\right)$ and Kane $\left(23^{\circ} 40^{\prime} \mathrm{N}\right)$ transform faults with the Mid-Atlantic ridge. Geochemistry, Geophysics, Geosystems 7(6):1-28, DOI $10.1029 / 2005$ GC001127

Xie Z, Matzen R, Cristini P, Komatitsch D, Martin R (2016) A perfectly matched layer for fluid-solid problems: Application to ocean-acoustics simulations with solid ocean bottoms. Journal of the Acoustical Society of America 140(1):165175 , DOI $10.1121 / 1.4954736$ 

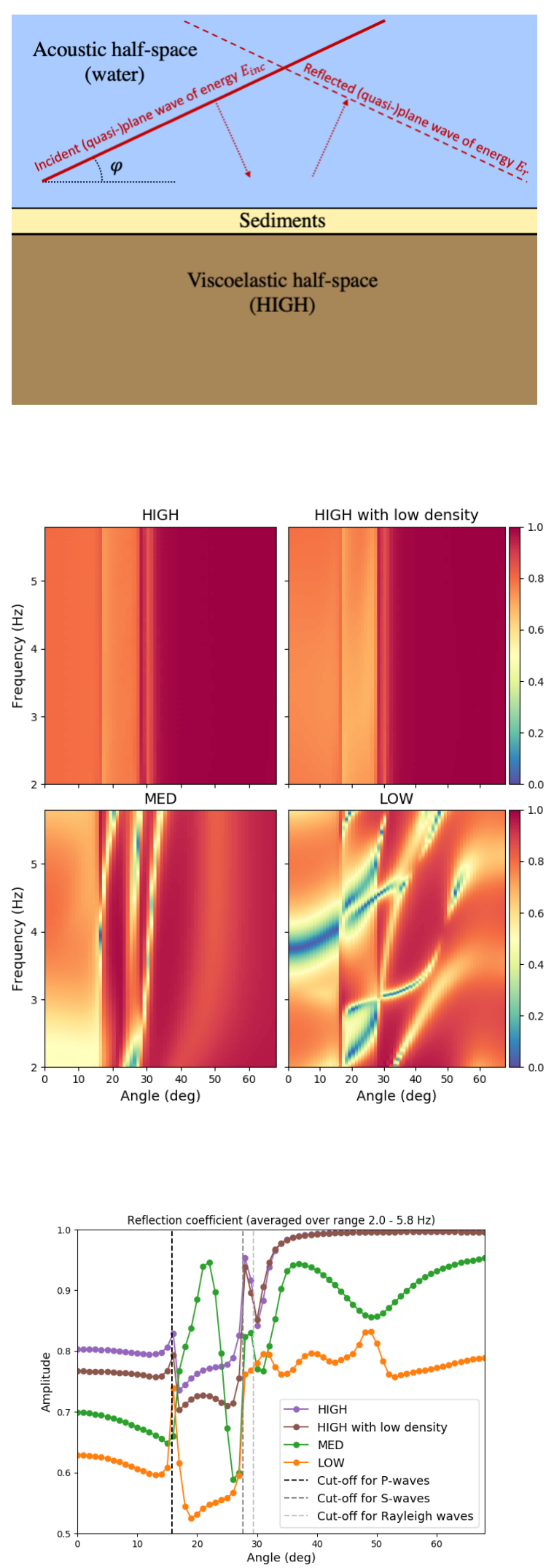

Fig. 5 Top: setting of the energy reflection coefficient shown below $\left(E_{i n c} / E_{r}\right)$. Middle: energy reflection coefficient for oceanic plane waves as a function of frequency and incidence angle $\varphi$ (defined in the top sub-figure) at the water-sediments interface for the cases described in Table 1. The frequency range shown corresponds to the bandwidth of the source. Bottom: same but averaged over the frequencies shown. 


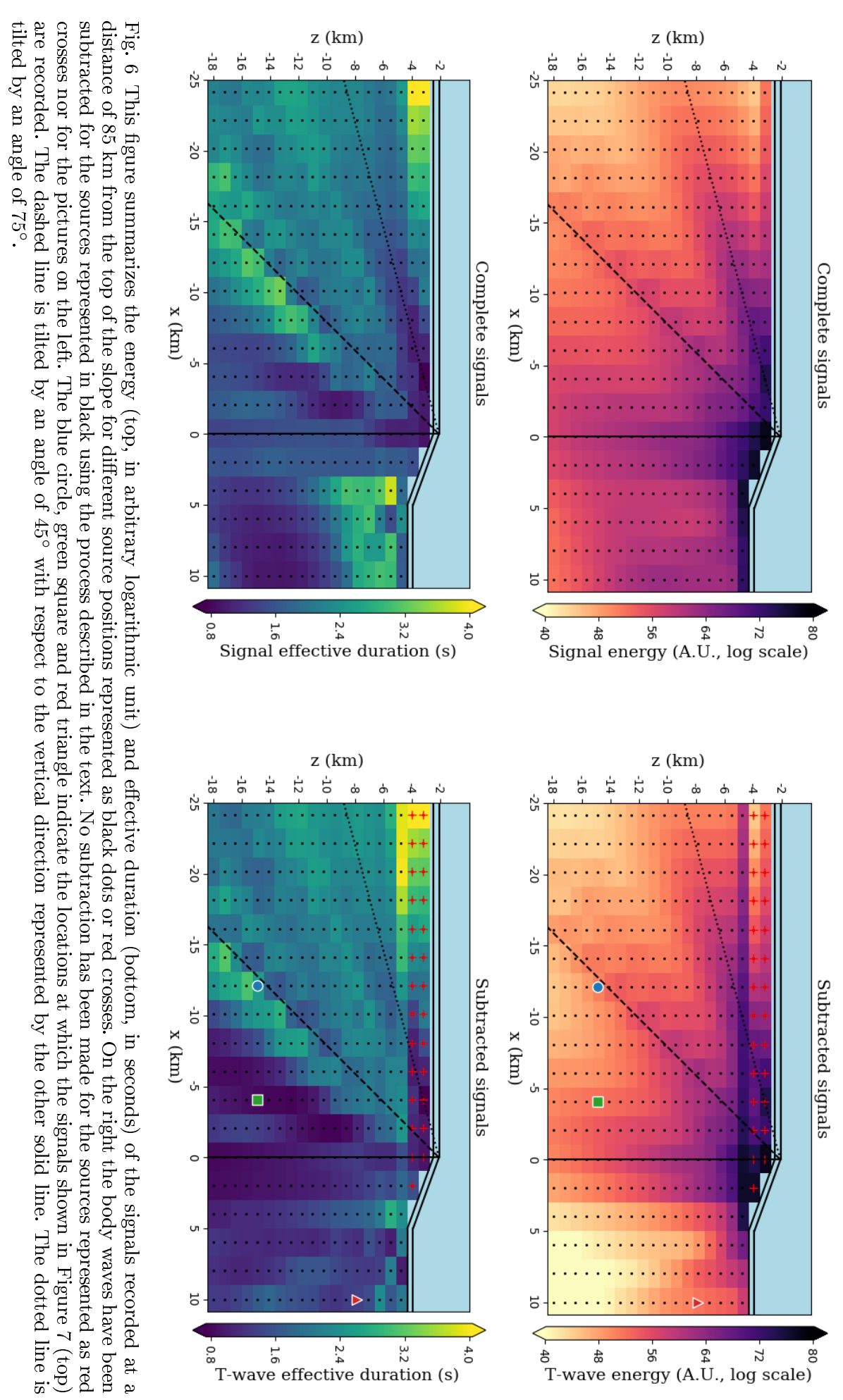



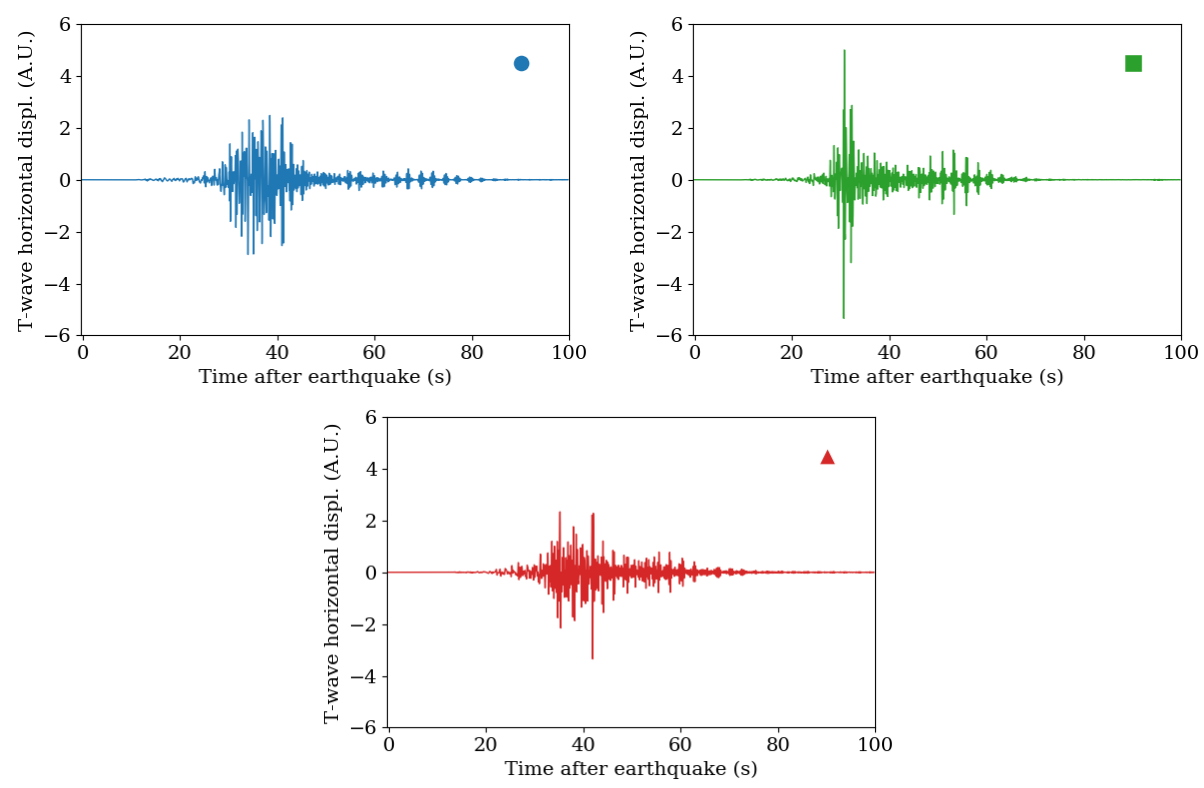

Fig. 7 T-wave horizontal displacement (after body wave subtraction) generated by the three earthquakes marked as a blue circle, a green square and a red triangle in Figure 6 respectively. The green signal is more impulsive compared to the blue and red ones. 